\title{
Nombramientos de escribanos públicos en Ávila, y sus circunstancias, en tiempos de los Reyes Católicos
}

\author{
Blas Casado Quintanilla \\ UNED
}

\begin{abstract}
RESUMEN
Recogemos aqui algunos de los abundantes testimonios que la documentación castellana de finales del siglo xv nos ha dejado acerca de los nombramientos de escribanos públicos, en este caso de Avila, a partir de tres supuestos: uno, nombramientos por defunción del escribano que ostentaba el oficio de escribania; dos, la pérdida del oficio por haber incurrido el escribano público, o sus ascendientes, en el delito de "judaizar"; tres, nombramientos debidos a situaciones especiales. Nos referimos, por último, a los abusos, protagonizados por las autoridades locales de algunas poblaciones, $y$ vinculados a la toma de posesión de escribanos públicos.
\end{abstract}

PALABRAS CLAVE

Escribanos, Nombramientos, Reyes Católicos, Ávila.

\section{ABSTRACT}

We gather here some of the abundant testimonies that the Castilian documents of the end of the $15^{\text {th }}$ century have left us, about the appointments of the Notaries publics, in this case of Avila, starting from three assumptions: first, the appointment of a new Notary public due to the death of the old one; second, the loss of the profession for committing the crime of judaize; third, the appointments for special situations. We mention, to finish, the abuses of the local authorities of some cities, in relation with the taking over of the Notaries publics.

\section{KEYWORDS}

Notaries publics, Appointments, Catholic Kings, Ávila. 
Hace cuarenta años que Filemón Arribas Arranz ${ }^{1}$ trazó las líneas maestras sobre el tema de los escribanos públicos en Castilla durante el siglo XV. Lo hizo con acierto y apoyándose no solo en los datos aportados por las Actas de Cortes de los Antiguos reinos de León de Castilla a lo largo del citado siglo, sino recurriendo en muchos casos a documentos de la aplicación del derecho. En la misma categoría de interés hay que situar los estudios realizados por José Bono Huerta ${ }^{2}$, quien nos dio a conocer los orígenes del notariado español y su evolución a través de los tiempos, con un análisis pormenorizado de todo tipo de fuentes históricas, sin olvidar las más diversas publicaciones y la literatura acumulados hasta aquellos días sobre otros tantos aspectos del notariado hispano.

Desde otras perspectivas, y sin ánimo de ser exhaustivos, el tema de los escribanos públicos ha sido tratado por Corral García ${ }^{3}$, Rábade Obradó ${ }^{4}$, varios autores ${ }^{5}$ de las universidades andaluzas que han estudiado desde diversos puntos de vista la figura del escribano público, o los variados enfoques que aparecen en otras recientes publicaciones ${ }^{6}$. Los estudios notariales pueden extenderse al análisis de muchos aspectos: el nombramiento de los escribanos, mecanismos de aprendizaje y acceso al oficio, los preceptos normativos que rigen el ejercicio de la fe pública, el comportamiento de los escribanos como grupo, etc. En esta ocasión centraremos nuestra atención en los nombramientos de los escribanos, analizando las cartas reales de merced, no solo en lo se nos indica desde la perspectiva del lugar de preparación y expedición de los documentos, sino también a partir de los datos proporcionados por esos diplomas reales en los que podemos encontrar noticias ciertas acerca de las posiciones y actitudes de las autoridades locales que son requeridas por los reyes para ejecutar o contribuir a ejecutar el mandato real.

\section{NOMBRAMIENTOS POR RENUNCIA VOLUNTARIA O «MORTIS CAUSA»}

La reina Isabel el dia 6 de diciembre de 1475 nombra a Alfonso de Quintanilla, contador mayor y de su Consejo, escribano público del número de la villa de Arévalo ${ }^{7}$

\footnotetext{
Filemón Arribas ArRanz, "Los escribanos públicos en Castilla durante el siglo xv", en Centenario de la Ley del Notariado. Sección Histórica, Vol. I, Madrid, 1964, págs. 165-260. También es de interés conocer el articulo publicado en el mismo volumen y firmado por José MARTinEz GiJon, "Estudios sobre el oficio de escribano en Castilla durante la Edad Moderna", pags., 261-340.

2 José BOnO, Historia del Derecho notarial español, Vol I-1, Madrid, 1979. y Vol. I-2, Madrid, 1982.

3 E. Corral Garcia, El escribano del concejo en la Corona de Castilla (siglos XI al xvil, Madrid, 1987.

4 M. P. Rabade Obradó. Origenes del notariado madrileño: los escribanos públicos en el siglo xV, Madrid, 2001

5 VV. AA. El notariado andaluz en el tránsito de la Edad Media a la Edad Moderna, Sevilla, 1996.

6 VV. AA. Perspectivas actuales sobre las fuentes notariales en la Edad Media, Universidad de Zaragoza, Departamento de Historia Medieval, Ciencias y Técnicas Historiográficas y Estudios Árabes e Islámicos, Zaragoza, 2004.

José Luis MARTin. Documentación medieval abulense en el Registro General de Sello (AGS), en la colección “Fuentes Históricas Abulenses», núm. 18, Institución Gran Duque de Alba, Ávila, 1995, págs. 76- 78 .
} 
porque había muerto el escribano Diego García. En este documento se determinan con claridad algunos de los pasos que en procesos de nombramientos de escribanos deben seguirse, aunque faltan otros, como veremos en un análisis comparativo con lo acaecido en otras ocasiones. Ahora se señala que el nombramiento tendrá valor "para en toda vuestra vida", y que las autoridades locales, "juntos en su conçejo", porque así es la costumbre, tomen juramento al citado Alfonso de Quintanilla o "a quien vuestro poder oviere", y que le den los derechos y salario que a su condición de escribano le corresponden.

Condiciones bien distintas aparecen en el documento del 3 de abril de 1476 por el que los Reyes Católicos nombran a Bartolomé Sánchez ${ }^{8}$, vecino de Çarahizes, escribano público del seismo de San Juan, Tierra de Ávila. Aquí se especifica, primero, que confían en "vuestra suficiencia e idoneydad"; segundo, que su nombramiento "es para en toda vuesta vida" y que se produce "por quanto renunçió y traspasó en vos" el escribano Pero González de Herrera; tercero, que el renunciante "nos envió suplicar e pedir por merced por su petiçión" que asi se hiciera; cuarto, que previamente se produjo "la renunçiaçión firmada de su nombre e signada de escrivano público".

Se indican, además, algunas normas de obligado cumplimiento por parte del nuevo escribano a fin de que su actividad notarial reúna las condiciones necesarias para la validez jurídica de la documentación por él preparada y expedida. Así debe cuidar que todas las escrituras que "ante vos pasaren... en que fuera puesto el día e el mes e el año e el logar donde se otorgaren..valan e fagan fe. "; y se añade que estas escrituras deben llevar "vuestro signo a tal commo este que nos vos damos...e vala e faga fe asy en juiçio como fuera dél" como elemento de validación. Nada nos sorprende que se le asigne un signo específico puesto que cada escribano tenía el suyo como elemento distintivo de autenticación de los documentos. Sorprende, en cambio, que una vez que en el dispositivo del documento se ha supuesto la "suficiencia e idoneidad" de Bartolomé Sánchez para ejercer de manera adecuada el oficio de escribano público, se le recuerde ahora que tiene que encabezar los documentos con la fecha completa y el lugar donde se escritura. Cabría pensar que se trata de una persona que gozaba de los suficientes conocimientos del derecho "teórico", al mismo tiempo que carecía de cualquier tipo de instrucción práctica, o dicho de otro modo, que no había aprendido el oficio de escribano público como "meritorio" al lado de un escribano público, camino muy frecuente para acceder al oficio de escribano. Cabría pensar que desde la Corte se está realizando una tarea de pedagogía o publicidad para fomentar el cumplimiento de una normativa notarial, quizá no cumplida, aunque ya la encontramos en las Partidas ${ }^{9}$.

8 Ibidem, págs. $82-83$

y Existía una larga tradición en lo que a esta normativa se refiere que ya encontramos en la Partida III, Tit. XVIII, ley LIV. 
Por un documento similar al anterior en casi todo ${ }^{10}$, y fechado el día 25 de abril de 1484, es nombrado Gómez Ferreras escribano público del número de Ávila, "para en toda vuestra vida» y porque renunció Pero López de Robles. En este caso se admite la renuncia al oficio porque es conforme a lo estipulado por las leyes, pero después de la data del diploma y a modo de postdata bien remarcada se añade esta cláusula: “... con tal quel dicho Pero López de Robles que faga e renunçie en él la dicha escribania y después de fecha la renunçiaçión aya bevido y biva el término de veynte dias contenido en la ley de Toledo e non en otra manera". Entre el nombramiento anterior y éste se ha celebrado las Cortes de Toledo de 1480, Cortes en la que se trató con detenimiento el tema de la sucesión en los oficios de escribanía ${ }^{11}$.

Sólo cinco años más tarde, con fecha del 4 de agosto de 1489, el escribano Gómez Ferreras, habia renunciado a su oficio de escribania a favor de Pedro de Chaves $^{12}$, vecino de Ávila, quien es nombrado escribano de número de la citada ciudad porque, de un lado, su idoneidad y suficiencia es conocida; y de otro, según escribe la reina Isabel por "algunos buenos servicios que me avedes fecho e en alguna hemienda e remuneración dellos". Se le recuerda que el nombramiento tendrá valor "para en toda vuestra vida"; que debe encabezar los documentos con los datos de la fecha y el lugar de escrituración; se le asigna su signo; y se manda al concejo de Ávila que tome el correspondiente juramento al nuevo escribano y se le respeten los derechos que le correspondan.

No se hace referencia a las leyes de las Cortes de Toledo de 1480 relativas al plazo que ha de transcurrir entre la renunciación y su muerte, porque no es el caso. Pero aparece un nuevo elemento, que también fue recogido en las leyes de las citadas Cortes ${ }^{13}$, según las cuales para mostrar la idoneidad era necesario que el

10 Tomás Sobrino ChOMOn. Documentación medieval abulense en el Registro General del Sello (AGS), en la colección "Fuentes Históricas Abulenses», núm. 20, Institución Gran Duque de Alba, Avila 1993, págs, 69-70

1 Cortes de los Antiguos Reinos de León y de Castilla, Real Academia de la Historia, Madrid, 1882, Vol. IV, págs. 139: "Muchos fraudes se fazen en la renunciación de los oficios públicos, e quando algún ome que tiene oficio público se vee a la muerte e que non lo puede tener por sy, entonces lo renuncia e otros procuran con él que faga renunciación, e esto entiende en perjuizio de nuestra real preheminencia e en daño de la república; por ende, ordenamos e mandamos que de aqui adelante la renunciación que alguno fiziere de su oficio que touiere, non vala, salvo sy biuiere veynte dias después que otorgue la tal renunciación, o de otra guisa, que nos podamos proveer del dicho oficio, sin embargo de la tal renunciación e de la provisión que por virtud de ella se diere, asi como proveyéramos sy nunca la tal renunciación interuiniera".

12 Blas Casado Quintanilla, Documentación medieval abulense en el Registro General del Sello (AGS). en la colección «Fuentes Históricas Abulenses», núm. 22, Institución Gran Duque de Alba, Ávila. 1993. págs., 145-146.

13 Cortes de los Antiguos Reinos de León y de Castilla, Real Academia de la Historia, Madrid, 1882, pág. 146. "Con gran justicia nos es suplicado por los dichos Procuradores que proueamos sobre la confusión que ay por razón de los muchos escribanos por todas partes de nuestros reynos; por ende, queremos e ordenamos que de aqui adelante no se dé titulo de escriuania de cámara ni de escriuania pública a persona alguna, slauo si fuere la tal persona vista e conocida por los del nuestro Consejo, e precediendo para ello nuestro mandamiento. e fuere por ellos examinado e fallado que es ábile e idóneo para exercer el tal oficio, e que la carta de escribania sea firmada en las espaldas a lo menos de tres letrados de los diputados del nuestro Consejo... e mandamos otrosí a las personas para quien se dieren las dichas cartas, que no usen de los tales oficios de escriuania, saluo si las houieren en forma susodicha, so pena que sean auidos por falsos e pierdan la mitad de sus bienes para la nuestra cámara...". 
nuevo oficial, en este caso, el nuevo escribano, superara las prueba mediante un examen y que se hiciera constar en las espaldas del mismo documento de nombramiento; así ahora podemos leer cómo el escribano del registro a quien correspondió asentar este nombramiento, sin duda conocedor de la ley, no se olvidó de copiar e incluir al final del texto la nota siguiente: " $E$ en las espaldas estava escripto: ábile e en forma. Rodericus, doctor", en clara referencia al hecho de haber superado el examen correspondiente.

Con fecha del 7 de abril de 1490, los reyes nombran a Juan de Cabrera ${ }^{14}$, vecino de Arévalo, "para en toda vuestra vida", porque confían en su suficiencia y habilidad, como "nuestro escrivano e nuestro notario público en la nuestra corte e en todos los nuestros reynos e señorios". El nombramiento tiene un carácter totalmente distinto a los que hemos visto hasta ahora. Ya no ha de ser jurado por el concejo sino reconocido como escribano y notario por todos, desde los "Infantes, perlados..." hasta los "omes buenos de todas las çibdades e villas e logares de los nuestros reinos e señorios...". Se le recuerda que debe encabezar correctamente los documentos, se le señala cual sea su signo de escribano, pero se distancia de los otros escribanos públicos al vincularlo a la Corte indicando algunos tipos documentales muy característicos, como "todas las cartas e obligaciones e contratos e alvalaes e nómynas... e otras qualesquier escrituras...", que quedan dentro de sus competencias y le vinculan a la Corte y que, sin embargo, rebasan el ámbito de acción de los escribanos públicos de las distintas ciudades y villas del reino

Gómez de Robles, vecino de Ávila, «nuestro contador mayor e del nuestro consejo: es nombrado escribano público del número de Ávila para toda su vida ${ }^{15}$, "por los muchos e buenos e leales servicios que me avedes fecho e fazedes de cada día", y porque había muerto el escribano Juan Rodríguez Daza. Se le obliga al juramento del oficio ante las autoridades locales y, sorprende que, aún conociendo el cargo que ocupa en la Corte, se le recuerda que ha de encabezar las escrituras con la datación y el lugar; sin duda porque ya está muy elaborado el desarrollo clausular de los documentos de nombramiento y sin mirar a la persona a quien va destinado se copia la fórmula documental establecida.

Ya vimos más arriba cómo otro contador mayor y miembro del Consejo real había sido nombrado escribano público de Arévalo. Alli no encontramos ningún detalle que pudiera explicar la anomalía de que un tan alto personaje de la Corte pudiera ser nombrado oficial de mucha menor categoria, al mismo tiempo que permanecía en su oficio cortesano. Tanto en aquélla como en esta ocasión se trata de cubrir una vacante por defunción del escribano anterior. Alli no se nos indica que Alonso de Quintanilla fuera de Arévalo, aqui se expresa con toda claridad que el

in José Antonio Canales SAnchez, Documentación medieval abulense en el Registro General del SeIlo (AGS), en colección "Fuentes Históricas Abulenses", num. 28, Institución Gran Duque de Alba, Ávila, 1996, págs. 60-62. Similar nombramiento se produce a tavor de Juan de Valdés, vecino de Cebreros, "aldea e termino de la çibdad de Ävila", págs. 125-126.

15 lbidem, págs, 81-82. 
derecho le asiste a Gómez de Robles pues es vecino de Ávila. Ahora se nos proporciona un dato que puede servir de explicación a nuestra cuestión: "Otrosy, mandamos al corregidor e justicia de la dicha çibdad que fagan a los hijos e herederos del dicho Juan Rodríguez Daza que vos den e entreguen todos los registros del dicho Juan Rodriguez Daza, para sacar de ellos las escripturas que ante él pasaron, para las dar sygnadas a las partes que las pidieren, pagándoles los derechos que ovieren de aver por el registro; e que les cumpla e apremie a ello". Tan evidente es que había un conflicto no menor, como que los registros y notas de los escribanos ${ }^{16}$ "nunca fueron consideradas propiedad privada de los escribanos" ${ }^{1}$, sino propiedad del oficio. Se nombra a los hijos pero también a los herederos, por tanto de herencia se trataba. Estos o querían heredar la escribania o pedian una cuantía muy grande por los derechos sobre el registro de su padre; es más, o tenían a alguna persona interesada en la escribanía que les hubiera ofrecido una cantidad por los derechos del registro y que ya había sido negociada y aceptada por ellos. El encargo de reclamar los registros se le hace al corregidor y a la justicia, elemento que unido al apremio del que se hace mención en la carta real pudiera explicar que algún asunto de mucha importancia estaba siendo retenido porque "los hijos y herederos" se negaban a que se expidieran determinadas escrituras y no se les pagara lo fijado por su padre para este trabajo concreto.

El tema continúa. El dia 15 de agosto de 1490, los reyes nombran a Juan Serrano, "nuestro maestresala" y vecino de Ávila, escribano de número de Ávila ${ }^{18}$. Es una persona idónea y suficiente; ha hecho muchos servicios y los sigue haciendo a los reyes por lo que se le nombra "en alguna enmienda e remuneración dellos"; se le indica que ha de encabezar las escrituras con la fecha y determinación del lugar; se le entrega su signo de escribano público; se le nombra porque ha muerto el escribano Pedro Gutiérrez de Ávila. Se manda al concejo que le tomen juramento según que lo tienen por costumbre, pero con este aviso: "syn nos más requerir ni consultar sobrello nin esperar otra nuestra carta nin mandamiento". La tensión está servida; las autoridades locales no están de acuerdo con este nombramiento o con la política de nombramientos que se sigue desde la Corte en relación con Ávila, sin que seamos capaces de formular ahora cuáles eran las razones que se esgrimian por parte de las autoridades locales abulenses.

De nuevo se ordena al corregidor y justicias que reclamen, a quien los tenga, los registros de todas las escrituras que pasaron ante el escribano Pedro Gutiérrez de Ávila, y se los entreguen a Juan Serrano para que este pueda expedir los documentos a partir de las notas de sus registros. No se hace mención a hijos o herederos ni a que se le de los honorarios correspondientes a persona alguna. Por tanto en este caso no se trata de tasar el valor de los posibles derechos que pudieran proporcionar los registros.

16. Partida III, Tit. XVIII, ley LV.

17 Filemón Arribas ARRanz, "Los escribanos públicos en Castilla durante el siglo XV", en Centenario de la ley de Notariado, Sección Histórica, Vol. I, pág. 214.

18 Ibidem, págs. 100-101 
Los nombramientos de Fernando de la Fuente como escribano público de Fontiveros ${ }^{19}$, y de Gonzalo de Olivares como escribano público de Ávila ${ }^{20}$ obedecen a los formularios ya conocidos. No así el de Francisco de Pajares ${ }^{21}$ que es nombrado escribano público "del seysmo de Santo Tomé, término e jurediçión de la çibdad de Ávila» después que el escribano Juan Gómez de Pajares, su padre ${ }^{22}$, renunciase en su favor, y reconociendo de manera expresa "vuestra suficiencia $e$ avilidad e los buenos servicios que nos avedes fecho...e en alguna hemienda e remuneración dellos". Tampoco en este caso se le asigna ningún signo propio al nuevo escribano público.

En el nombramiento de Fernando Guillamas ${ }^{23}$ encontramos los elementos habituales y algunas novedades. El rey Fernando acata la suficiencia y habilidad como en el resto de los casos, pero, a renglón seguido, destaca el concepto de " /egalidad". También se hace referencia a los servicios prestados, así como a la idea de remuneración de los mismos. Se le asigna el correspondiente signo notarial. Sustituye en la escribanía de número de Ávila al escribano Juan Serrano, maestresala, a quien ya vimos más arriba, porque había renunciado en su favor. Además de la renuncia personal de Juan Serrano, hecha en forma y tiempo, se añade un dato que no habiamos encontrado hasta ahora: "... asy mismo me embió suplicar e pedir por merced el regimiento de la dicha çibdad de Ávila, por su petición firmada de sus nombres". Cuando valorábamos el nombramiento de Juan Serrano sospechábamos que se había realizado para dar solución a un conflicto concreto en la ciudad de Ávila; ahora nos parece que la intervención directa del propio concejo abulense a favor de Fernando Guillamas y el añadido de «legalidad», nos autoriza a pensar que aquel nombramiento se realizó por la necesidad de dar la salida adecuada a un problema, cuya entidad aún se nos escapa. Nos puede ayudar a entenderlo el que cuando los reyes le dan "la posesión e casy posesión" y la "facultad» para ejercer su oficio, lo hacen, "en caso que por el dicho concejo, justicias, regidores e escribanos públicos...non seades resçibido". ¿Escribanos públicos? Si el regimierío lo había pedido o autorizado mediante su firma, cosa no habitual, $i$ quién había manifestado el impedimento de legalidad para el nombramiento de Fernando Guillamas?, ¿ los escribanos públicos del número de Ávila?

Por vía de hecho cuando los reyes Católicos el día 21 de mayo de 1491, nombran a Alonso de Mirueña ${ }^{24}$, escribano del seismo de San Pedro, Tierra y ju-

${ }_{14}$ Ibidem, págs, 128-129. Hay que señalar que sustituye al difunto escribano Francisco de la Fuente, aunque no se hace referencia ninguna a un posible parentesco. Nos sorprende que no se haga alusión al signo que ha de usar en la suscripción de los documentos preparados y expedidos por el nuevo escribano. El nombramiento del dia 6 de octubre de 1490.

20 Ibidem, págs, 142-143. Este nombramiento del dia 12 de noviembre de 1490 , se produce por renuncia de Gómez de Robles. Se le señala el signo que debe utilizar en la validación de sus escrituras.

21 ibidem, págs. 148-149.

22 FrancisCO TOMAS Y VALIENTE, "Origen bajomedieval de la patrimonialización y la enejenación de oficios públicos en Castilla», en Actas del I Simposium de Historia de la Administración Madrid, 1970, págs. $125-179$

23 ibidern, págs. 153-154.

24 Ibidem, págs. 183-184. 
risdicción de Ávila, en sustitución del finado Alfonso Garcia de Naharrillos lo hacen "porque a nos pertenece proveer de la dicha escribania", y lo repiten dos veces en el mismo documento. Podrian pensarse que esta repetición, esta insistencia en la defensa de un derecho real para realizar el nombramiento se debe a una redacción un tanto forzada de la correspondiente cláusula, lo cual es cierto en este caso; pero no podemos dejar de ponerlo en relación con las palabras que leemos más adelante: "Ca nos por esta dicha nuestra carta vos recibimos e avemos por recibido al dicho ofiçio e al uso e exercicio dél, e vos damos poder e facultad para lo usar exerçer caso que por el dicho conçejo o por alguna o algunas personas dél non seades recibido al dicho ofiçio". Ya hemos visto redacciones muy similares a esta en otros cartas de provisión, aunque no se había detallado con tanta claridad que «alguna o algunas personas" podrían oponerse. La tensión esta servida pues de un lado se menciona el derecho a proveer por parte de los reyes, y, de otro, se anuncia la posible oposición de los obligados a aceptar la provisión real; cabe preguntarse, la oposición anunciada hace referencia al acto concreto de proveer para un oficio de escribania, o se refiere al rechazo a que una determinada persona ejerza ese oficio.

La respuesta la encontramos en una provisión del día 4 de octubre de 1492 por la que los reyes nombran a Diego Sánchez ${ }^{25}$, vecino de Ávila, escribano del seismo de San Pedro de Ávila, en sustitución del escribano finado Alonso Garcia de Naharrillos. El documento parece una copia del anterior en el que el amanuense se ha contentado con cambiar el nombre del beneficiado. En menos de un año y medio un mismo escribano difunto es sustituido por dos nuevos escribanos. Cabe pensar que el primero se encontró con una tan fuerte oposición, según lo anunciado en su carta de nombramiento, bien por parte de las autoridades locales o bien por otras personas, que no pudo llegar a tomar posesión de su oficio.

\section{NOMBRAMIENTOS POR PÉRDIDA DE OFICIO A CAUSA DE HABER INCURRIDO EN EL DELITO DE «HERÉTICA PRAVEDAD»}

Pedro Juárez ${ }^{26}$ ha sido privado de su oficio de escribano público del número de la ciudad de Ávila el dia 13 de octubre de 1492, porque sus padres han sido juzgados y condenados por el delito de "herétyca pravedad"; no se indica si el juicio se había produce en vida o después de la muerte de los declarados culpables, pero en cualquier caso Pedro Juárez fue privado del oficio de su escribanía «segund derecho". Puesto que ha quedado vacante su escribanía a los reyes "pertenesçe proveer en el dicho ofiçio". El nombramiento recae a favor de Pedro Iñiguez de Sanmartín, "escrivano de secuestros de la Inquisición", una vez afirmada

25 Jose Luis MARTIN, Documentación medieval abulense en el Registro General del Sello (AGS), en la colección “Fuentes Históricas Abulenses”, núm. 29, Institución Gran Duque de Alba, Ávila, 1996, págs. 135-136.

26 Ibidem, págs. 137-138 
su suficiencia e idoneidad, cosa demostrada puesto que ya estaba ejerciendo de escribano. Ignoramos por qué razón deja la escribania que ocupaba en los tribunales de la Inquisición, para asumir la escribanía pública vacante en unas circunstancias, de alguna manera vinculadas a su anterior oficio, aunque no podemos por menos de señalar la vinculación. Pedro Iñiguez tendrá que ser jurado por las autoridades locales abulenses, como cualquier otra persona que accede a un oficio público.

Pedro Juárez viene obligado a entregar todos los «registros e protocolos e proçesos e todas las otras escripturas que ... al dicho su ofiçio son pertenesçientes", para que el nuevo escribano las pueda dar signadas; el principio de vincular los registros al oficio y no a la persona que ejerce el oficio tiene una importancia extraordinaria tanto por lo que se refiere a la conservación de los protocolos notariales, como por lo que toca a los honorarios que a la familia del escribano pudieran corresponder en el supuesto de que hubiera que expedir algunos documentos a partir de las "notas» o minutas recogidas en los libros de registro. A diferencia de otros nombramientos realizados "mortis causa" o por renuncia voluntaria, en este caso se omite la referencia a los derechos que pudieran corresponder al escribano sustituido por expedir las escrituras signadas a partir de los registros por él efectuados.

Francisco Rodríguez Daza ${ }^{27}$ pierde su escribania pública del número de la ciudad de Ávila por la misma razón jurídica que Pedro Juárez, aunque en circunstancias aún más extremas; se trata de dos difuntos cuyos «huesos son sacados e desumados". En procesos inquisitoriales separados, de un lado, su madre Isabel Rodríguez, y de otro, su padre Fernando González Daza, ambos han sido declarados culpables de la "Herética pravedad". La condena atañe no sólo a las personas encausadas y condenadas, sino que se extiende a su descendencia. En el documento de condena referido a la madre se dice que "segund derecho, sus hijos ... quedaron e son inhábiles e incapaces para tener beneficios ni ofiçios públicos"; en el documento condenatorio referido a su padre se amplia de manera considerable el perjuicio para los descendientes ya que se dice: "sus hijos y sus nietos del dicho Fernando Gonçalez quedaron e son inhábiles... para tener ofiçios públicos". Por lo que el oficio de escribano público de Francisco Rodríguez Daza "es confiscado e aplicado a nuestra cámara e fisco".

El nuevo nombramiento de sustitución fue expedido el día 10 de julio de 1493 , recae en Pedro de Vegil, vecino de Ávila y platero de los reyes; se conservan dos nombramientos, en dos documentos distintos, uno referido al proceso de su madre y otro referido al proceso de su padre, con alguna variación de interés. Pedro de Vegil debe su nombramiento a que goza de la suficiencia y habilidad necesaria para ejercer el oficio al que es proveido y en remuneración de los muchos servicios

Carmelo LuIS López, Documentación medieval abulense en el Registro General del Sello (AGS), en la colección "Fuentes Históricas Abulenses", núm. 30, Institución Gran Duque de Alba, Ávila 1995, págs. 183-187. 
prestados. Se nos antoja pensar que, o bien ganaba poco como platero y esperaba ganar más como escribano público de número, o bien era de mayor prestigio el oficio de escribanía que el de plateria, o bien se le había truncado el camino a la escribania en alguna ocasión y no quería perder ahora la ocasión de ejercer tal oficio. Cabe también preguntarse, en este caso, ¿ quien fue el causante del inicio de estos procesos que terminaron con la exhumación de sus huesos de los hallados culpables? La pregunta es pertinente porque tanto Isabel Rodríguez como su esposo Fernando González ya estaban muertos y, si habían judaizado en vida, el que o los que supieran que eran judaizantes habían tenido tiempo de delatarlos y perjudicarles en su honor y hacienda, mientras que ahora, una vez muertos, ya no se podía hacer nada contra ellos; a no ser que se pretendiera hacer mucho daño a los descendientes de aquellos herejes, pero no a los propios herejes, quienes, según la ley, debian ser condenados. La pregunta seria: cui prodest?

Se le reclaman y se apremia al escribano destituido para que entregue los registros y no se fija ningún derecho que pudiera derivarse de sacar las escrituras a partir de los protocolos y registros elaborados por Francisco Rodríguez Daza, puesto que todo, oficio y escrituras, es confiscado.

No permaneció Pedro Vegil ${ }^{28}$ mucho tiempo en la escriban pública de Ávila. El día 10 de agosto de 1497, los reyes nombran escribano público del número de la ciudad de Ávila a Andrés Gutiérrez Egas, porque es suficiente e idóneo y por los muchos servicios prestados y los que prestará.; precisamente la escribanía a ocupar es la de Pedro Vegil, quien habia renunciado en tiempo y forma a favor del citado Andrés Gutiérrez Egas.

Francisco Álvarez ${ }^{29}$ también pierde su oficio de escribano público del número de la ciudad de Ávila el día 31 de julio de 1493 porque Gonzalo Álvarez, su padre, habia sido condenado "por el delito de herética pravedad". Los reyes, una vez enunciado el principio de que a ellos corresponde «proveer» en el citado oficio, expiden el documento de nombramiento a favor de Alonso de Cogollos. Los reyes reconocen la idoneidad y suficiencia del beneficiario, así como la necesidad de remunerar, de alguna manera, los muchos servicios prestado a la Corona. Entre las cualidades personales atribuidas a Alonso Cogollos se enumera, además, la de la "legalidad", cualidad que es esgrimida en muy contadas ocasiones en los nombramientos de escribanos públicos, y que usada en esta circunstancia reclama nuestra atención. Así en el mandato real para que se tome el juramento acostumbrado por parte de las autoridades locales, entre éstas se incluye no solo a los oficiales y hombres buenos de la ciudad, sino también a "los escribanos públicos del número della... juntos en su cabildo e concejo e ayuntamiento, segund lo han de

28 María Dolores CABAÑAS GonzAl.Ez, Documentación medieval abulense en el Registro General del Sello (AGS), en la colección "Fuentes Históricas Abulenses", núm. 35, Institución "Gran Duque de Alba", Ávila 1996, págs. 89-91.

${ }^{29}$ Carmelo LUIS LOPEZ, Documentación medieval abulense en el Registro General del Sello (AGS), en la colección «Fuentes Históricas Abulenses», num 31, Institución Gran Duque de Alba, Ávila 1996. págs. 14-16. 
uso e de costumbre, tomen e reçiban de vos el juramento..."; sabemos quienes componen el concejo y el ayuntamiento; pero ignorábamos que el "cabildo de escribanos", también tuviera que tomar juramento a los nuevos escribanos del número. La tensión va en aumento cuando observamos que en el momento en el que leemos en el documento por el que los reyes le dan "la posesyón e casy posesyón" del oficio, dicen que lo hacen por si llegara el "caso que por el mismo conçejo, justicias, regidores e otros ofiçiales de la dicha çibdad", y añade: "e por los otros escribanos públicos del número della o por alguno dellos a él ofiçio non seades recibido...". Los escribanos ya han consolidado su poder y capacidad para intervenir en la "toma de posesión" de los nuevos escribanos públicos del número de Ávila. A continuación, como en los casos anteriores, se le apremia al escribano sustituido a que entregue todos los registros y escrituras por él realizadas en el ejercicio de su oficio.

Alonso Álvarez ${ }^{30}$ es privado de su escribanía de número de la ciudad de Ávila el día 29 de marzo de 1494, porque sus padres Pero González Dalponte y su mujer fueron condenados por el delito de "herética prabedad". Los reyes, en el ejercicio de sus expresamente declaradas atribuciones, nombran a Cristóbal Ordóñez como escribano del número de la citada ciudad, porque reúne las cualidades de suficiencia e idoneidad, además de las de "legalidad", y la de haber prestado y prestar muchos servicios. El documento guarda el mismo esquema que el anterior en su desarrollo clausular y con el mismo contenido en cada una de sus cláusulas tanto en los referente al juramento del nuevo escribano por parte de las autoridades locales y de los escribanos públicos del número de la ciudad, como en lo que toca al tema de los registros notariales.

Es pertinente ahora que retrocedamos en el tiempo y nos situemos en el año 1485. Este año unos diputados del Concejo de la ciudad de Ávila, presididos por el corregidor y con la participación de regidores, letrados del concejo, miembros del estamento eclesiástico y del común, y con la ausencia de los escribanos públicos del número de la ciudad, comenzaron a elaborar unas Ordenanzas a partir de las ya existentes; en parte retocaron éstas, pero también elaboraron otras nuevas ${ }^{31}$. Esta «diputación» reguló en las citadas ordenanzas la actividad agrícola, la vida artesanal y comercial, el orden público, la higiene y limpieza de las calles, etc.; y, en lo que a nosotros interesa, estableció los "honorarios" de los escribanos públicos de la ciudad ${ }^{32}$, asignando una tarifa para cada uno de los tipos documentales que alli se enumeran. Finalizado su trabajo, el concejo en 1487 hizo públicas las Ordenanzas elaboradas.

Los escribanos públicos de Ávila no quedaron conformes con la tasación establecida en la Ordenanzas para algunos de los tipos documentales que ellos

30 Ibidem, págs. 165-167.

31 José María Monsalvo Antón, Ordenanzas medievales de Ávila y su Tierra, en la colección «Fuentes Históricas Abulenses", núm. 5. Institución "Gran Duque de Alba", Ávila 1990.

32 Ibidem, págs.163-166. 
debian preparar y expedir, sino que protestaron porque "todos los dichos escrivanos se avian agraviado diciendo aver sido en su perjuizio e de los dichos sus ofiçios". El corregidor y regidores y el resto de los miembros que habían participado en la elaboración de las Ordenanzas, aceptaron las quejas de los escribanos públicos y volvieron a tratar el tema de los "honorarios" de los escribanos públicos en algunos tipos documentales. De parte de los escribanos públicos participaron: Fernan Sánchez Pareja y Juan Rodríguez Daza que eran, además de escribanos públicos del número de la ciudad, escribanos del concejo, más Juan de Arévalo, Juan Álvarez, Francisco Rodríguez y Pedro Xuárez, en nombre del "cabildo de los escrivanos" 33 . En otro momento de este proceso de reelaboración de las Ordenanzas en lo que afectaba a a la "tabla de derechos" de los escribanos en el ejercicio de su oficio, leemos lo siguiente: "E luego Juan de Arévalo e Juan Álvarez, e Ferrando Hortega e Francisco Rodriguez e Francisco Álvarez, por sí e en nombre del cabildo de los escrivanos públicos del número de la dicha çibdad, dixeron que consentian e consintieron en los dichos capitulos".

Concluimos este epígrafe señalando, primero, la coincidencia de nombres entre las personas que intervinieron como delegados del "cabildo" de escribanos y los referidos bajo este último rótulo referido a las sustituciones por haber incurrido sus ascendientes en el delito de "herética pravedad»; segundo, destacando, no sólo la importancia adquirida por la agrupación de escribanos, sino de algunas personas dentro de ese grupo de oficiales en el conjunto de los escribanos; tercero, que esas personas deberian contar con una autoridad, al menos moral, sobre el resto de miembros del oficio notarial; y cuarto, que estos posteriormente fueron apartados de sus oficios de escribanos públicos del número: Francisco Rodriguez Daza, Pedro Xuárez y Alonso Álvarez.

\section{NOMBRAMIENTOS CON CONNOTACIONES ESPECIALES}

Dejando a un lado otros nombramientos de escribanos por ser similares a los ya recogidos, nos detenemos en aquellos que presentan alguna novedad destacable. Es el caso de Luis Camporio ${ }^{34}$, hijo de Pedro González, cuando era soltero, ahora ya difunto, y de Isabel González, siendo soltera, ahora ya difunta, por lo tanto hijo ilegítimo y por consiguiente que "non podedes aver nin tener ofiçios públicos».

Luis Camporio había sido nombrado escribano público del número de la ciudad de Ávila por renuncia de Goméz González, "vuestro tyo" 35, pero esto había sucedido siendo hijo ilegítimo. Cabe pensar que este primer nombramiento a favor de Luis Camporio, nombramiento que no conocemos, no debió de tener efecto en Ávila, donde conocian la situación legal del beneficiado Luis Camporio, razón por

33 Ibidem, págs. 170-174

34 Carmelo Luis Lopez, obr. cit., num. 31, págs. 79-81.

35 Francisco TOMAS Y VALIENTE, Obr. cit. 
la cual el interesado debió presentar su súplica ante los reyes, indicando la situación en la que se encontraba. Pero por los muchos y buenos servicios prestados, que sin duda debieron de ser de esa categoría, porque con fecha del 21 de octubre de 1493, el rey Fernando escribe legitimando al citado Luis Camporio "solamente para que podades tener e obtener e tengades e obtengades el dicho ofiçio de escribania pública de la dicha çibdad de Avila... y esta merced e legytimación vos fago de mi proprio motu e çierta ciencia e poderyo real absoluto de que en esta parte quiero usar e uso", revocando algunas leyes de las que se hace relación en el dispositivo documental y que no recogemos porque no hacen al caso.

No tenemos por ahora noticias de lo que pudo haber ocurrido al escribano público del número de Ávila Gómez González ${ }^{36}$, entre el 21 de octubre de 1493, fecha en la que ya había renunciado a su escribanía abulense, y el 10 de agosto de 1497, fecha en que nos enteramos que estaba desterrado y enfermo ${ }^{37}$. Con anterioridad a esta última fecha Gómez González ha demandado de los reyes el permiso necesario para regresar a su casa de la ciudad de Ávila por razones de salud; los reyes le conceden que pueda irse a su casa a curarse, al mismo tiempo que mandan al corregidor de Ávila que se informe acerca del estado de salud de Gómez González, así como de cualquier otra cosa concerniente a la persona y se lo comunique a los reyes; la licencia para regresar a su casa es para un periodo de "treynta días e non más".

\section{NOMBRAMIENTOS Y ABUSOS CONTRA ESCRIBANOS}

En Arévalo, como en todas partes, los oficiales de nuevo nombramiento debían presentarse ante el concejo para ser jurados y tomar posesión de sus respectivos oficios. Estas autoridades locales, según parece, habían establecido que cada nuevo oficial con nombramiento real que se incorporase al concejo estaba obligado a «dar» una comida, o su equivalente en dinero, a cambio de ser admitido entre los oficiales del concejo. Asi se constata por una carta de los Reyes Católicos que, dirigida "al conçejo, justicias e regidores de la villa de Arévalo", dice que "vosotros no los queréys recibir a los dichos ofiçios syn que os den una comida o lo que pueda costar, e que esto asi lo llevays del que tiene poco como del que tiene mucho". Esta forma de actuar de las autoridades locales de Arévalo queda prohibida por los reyes "aunque digáis que lo tenéis de uso e de costumbre" ${ }^{38}$. La prohibición alcanza tanto a las autoridades locales como a los oficiales "proveidos», tanto a los beneficiados por el abuso, como a los perjudicados. Al-

\footnotetext{
3t María Dolores Cabanas Gonzalez, Documentación medieval abulense en el Registro General del Sell (AGS), en la colección “Fuentes Históricas Abulenses», núm. 35., Institución Gran Duque de Alba, Ávila, 1996., págs, 91-92

37 Carmelo LuIS LOFEZ, Obr. cit, núm 31, págs. 91-92.

36 José Maria Monsalvo Anton. Documentación medieval abulense en el Registro General del Sello (AGS) en la Colección "Fuentes Históricas Abulenses", núm. 36. Institución Gran Duque de Alba, Ávila 1995, págs. 161-162. El documento es de 16 de diciembre de 1498.
} 
canza también al escribano del concejo a quien se le impone la obligación de copiar la carta real de referencia "en los libros del conçejo de la villa e lo notifique a la justicia e regidores della cada e quando fuere necesario". No podemos determinar quienes debian de ser los beneficiados de la invitación del nuevo oficial, en nuestro caso, del nuevo escribano.

Los reyes dicen que han sido informados acerca de este tema, sin especificar cual es el origen de la información. Seguro que a la reina lo que le sobraban eran fuentes de información sobre este y otros muchos temas. Pero la información pudo venir por vía oficial. Con fecha 18 de septiembre de 1498 la reina nombraba al bachiller Juan de Arenillas ${ }^{39}$ como juez de residencia del corregidor saliente de Arévalo. Al citado bachiller se le conceden treinta dias para hacer el juicio de residencia y otros veinte para que la información llegue a la Corte.

Con cuatro dias de distancia con relación al caso de abuso genérico sobre oficiales que se recoge en el documento anterior, los reyes escriben al "que es o fuere nuestro corregidor o juez de residencia de la villa de Arévalo" 40 sobre la misma idea pero expresamente referido a un escribano público, con nombre y apellidos. Ahora la fuente de información le llega por un particular muy interesado en el tema. Sancho García de Villalpando ${ }^{41}$, se habia quejado a los reyes porque él había sido nombrado escribano público de Arévalo, hacía más de tres años, pero nunca había tomado posesión del cargo, antes al contrario, él había renunciado en otra persona de quien "los regidores e vecinos desa villa recibieron un yantar diciendo que de costumbre» lo tenían. Pero es que ahora, en la fecha de la carta querían las autoridades de Arévalo que Sancho García de Villalpando también les invitase por razón de haber sido nombrado aunque «no usó ni residió el dicho ofiçio". Los reyes ordenan ahora al corregidor, como respuesta a la carta de Sancho García de Villalpando, que no consienta con esta práctica de exigencia de una comida por la toma de posesión del oficio de escribano público; es más, si ya se ha producido el "yantar» que se le devuelva "lo que asy le costó la dicha comida".

Sabemos $^{42}$ que el día 26 de febrero de 1499, los reyes vuelven a interesarse por este tema porque Sancho García de Villalpando les ha notificado que el corregidor de Arévalo no ha cumplido lo mandado por la carta anterior. Conocemos también en esta fecha que son los regidores de Arévalo los que «han comido el yantar» a costa del referido Sancho y que los propios regidores han suplicado ante la Corte porque "lo tienen de uso e de costumbre de llevar los dichos yantares de las dichas escribanías" y no quieren restituir lo gastado; es más, los regidores se ausentaron de la ciudad a la espera de la respuesta real a su reclamación. Con

39 Ibidem, págs. 120-122.

40 Ibidem, págs. 168-169. Documento de 22 de diciembre de 1498.

"I Ibidem, pág. 169. Sancho era "secretario de la ilustrisima princesa doña Margarita, nuestra muy cara e muy amada hija"

4: Juan Jacinto Garcia PÉREz, Documentación medieval abulense en el Registro General del Sello (AGS) en Colección "Fuentes Históricas Abulenses" núm. 37, Institución Gran Duque de Alba, Ávila, 1996. págs. $37-39$ 
todo, "visto en el nuestro consejo" los reyes por medio de una sobrecarta ordenan al corregidor que "guardedes e cumplades e esecutedes e fagades guardar e complir e esecutar en todo e por todo según que en ella se contyene". Los reyes consideran que hay que eliminar este abuso de las comidas y la cláusula penal del documento es de este tenor: "so pena de la nuestra merced e de çinquenta mill maravedis para la nuestra cámara, con aperçibimiento que vos fazemos que sy non lo fiziéredes e compliéredes que a vuestra costa encomendaremos a persona de nuestra corte que asy lo faga e cumpla e esecute en vos la dicha pena” "43.

\footnotetext{
4:3 José Maria Monsalvo Antón, Documentación medieval abulense en el Registro General del Sello (AGS), en la Colección «Fuentes Históricas Abulenses», núm 36, Institución Gran Duque de Alba, Ávila, 1995, págs. 139-141. Se publica un documento correspondiente a Segovia relacionado asi mismo con el tema de los abusos que tratamos. Según el citado documento del 8 de octubre de 1498, los reyes enviaron al bachiller Fernando Gómez de Herrera a Segovia para ufazer pesquisa sobre lo de las doblas que los regidores de la dicha çibdad llevaron a los escrivanos públicos que nuevamente resçibian e re. cibieron por escrivanos". Estos regidores, por mandato real, estaban obligados no sólo a restituir las doblas cobradas a los escribanos públicos por razón de su incorporación al cargo de escribanos, sino que esta obligación alcanzaba también a pagar el sueldo del pesquisidor y del escribano que le acompañaba. Una y otra parte fue pagada por los regidores en cumplimiento del mandato real, no de su propio pecunio, sino de dinero de los propios de la ciudad. Por añadidura, los regidores apelaron enviando a la Corte al Licenciado del Espinar, también a costa de los propios de la ciudad, para defender sus pretensiones de pagar con el dinero del común. Pero el dispositivo de la carta real no deja lugar a dudas: Lo qual visto por los del nuestro consejo, porque paresçió que los dichos salarios non se devian pagar de la renta de los propios. salvo de sus propias faziendas de los que asy fueron culpados a restitución de las dichas doblas y que los que lo libraron non fizieron lo que devian como buenos regidores, fue acordado que devian mandar que los dichos siete mill e noventa e çinco maravedis, que asy se dieron en la forma sobredicha, que los restituyesen e tornasen la justicia e regidores que libraron el dicho salario a los dichos bachiller de Herrera e su escribano e al dicho licenciado del Espinar, para los propios desa dicha çibdad..... Y si dar e pagar los dichos maravedís non quisieren, executad en ellos e en sus bienes e de cada uno dellos por la parte que les cupiere e vendedlos e rematadlos en publica almoneda.....
} 